\title{
Managerial Networking and Stakeholder Support in Public Service Organizations
}

\author{
Rhys Andrews $^{1} \cdot$ Malcolm J. Beynon ${ }^{1}$
}

Published online: 19 January 2016

(C) The Author(s) 2016. This article is published with open access at Springerlink.com

\begin{abstract}
Resource dependence theory suggests that to function successfully, organizations must obtain certain resources controlled by actors in their environment. To do this effectively, managers often develop networking relationships with key stakeholder groups in order to make critical resources available. Managers in public service organizations, in particular, are frequently under great pressure to network with relevant actors from stakeholder groups in order to build support for service (co)production and legitimacy for strategic and operational decisions. To identify networking strategies which are conducive to stakeholder support, we explore the networking behaviour of over 1,000 English local government managers. Fuzzy cluster analysis identifies four distinctive, though inter-related types of managerial networking: technical, reputational, political, and tokenistic. The cluster membership functions from this analysis are used to examine the relationship between types of networking and stakeholder support in depth. The results of hierarchical regression analysis suggest that technically-orientated networking is the most conducive to stakeholder support, with tokenistic networking the least conducive.
\end{abstract}

Keywords Networks $\cdot$ Stakeholders $\cdot$ Local government $\cdot$ Empirical analysis

\section{Introduction}

Resource dependence theory suggests that organizations continually seek to acquire control over external resources held by other actors and organizations within their environment in order to minimize their dependence on those entities (Pfeffer and

Rhys Andrews

AndrewsR4@ cardiff.ac.uk

Malcolm J. Beynon

BeynonMJ@cardiff.ac.uk

1 Cardiff Business School, Cardiff University, Cardiff CF10 3EU, UK 
Salancik 1978). By reducing their resource dependence, organizations can attain greater control over their own destiny and so build an ever stronger power base making them immune from external threats. Only by securing as high a degree of autonomy as possible from the vicissitudes of its stakeholders can the survival of an organization be guaranteed (Pfeffer 1987).

There are several strategies organizations can adopt to lessen resource dependence, ranging from internal restructuring of one sort or another to the co-optation of external board members (Oliver 1991; Pfeffer and Salancik 1978). Critical amongst these tactics of resource acquisition though, are those activities, which alter the pattern of exchanges between an organization and the key stakeholders within its environment. Since organizations are open systems comprised of external as well as internal coalitions, social exchanges are at the heart of the processes through which intra and interorganizational structures of order are negotiated (Scott 2003). Thus, patterns of external managerial networking with key stakeholders are likely to play a large part in determining the relative success with which an organization interacts with its environment.

The need to manage environmental dependencies is becoming ever more important as the boundaries between organizations and their stakeholders become increasingly fuzzy, perhaps nowhere more so than in the public sector where the recent 'turn' towards networked forms of governance and service delivery has been an especially profound and decisive one (Agranoff and McGuire 2003; Molin and Masella forthcoming). Managers in public service organizations are now expected to proactively engage with the demands posed by this increasingly complex and challenging environment. In addition to managing the delivery of services, implementing national policies and responding to the demands of service users and citizens, public service managers now devote ever more time to engaging with actors in other service delivery organizations in the public, private and voluntary sectors (Henttonen et al. forthcoming). Indeed, in recent years there has been a dramatic shift away from bureaucratic and market-based modes of service delivery towards network models of public organization, which connect multiple diverse groups of actors in the pursuit of enhanced responsiveness to user needs (Molina forthcoming; Sargent 2011). Accordingly, the managerial skills and behaviours required to ensure public services effectively manage their stakeholder environment have also evolved, with the expectation that better networked managers will be able to reap the benefits of greater stakeholder support for their strategic and operational decisions.

The increased reliance on network models of governance and service delivery places great emphasis on the ability of public managers to cultivate collaborative relationships with a diverse range of important actors in order to access key resources of time, money and legitimacy (Agranoff and McGuire 2001). Yet in many respects, little is still known about the networking behaviour of public managers, especially about broad patterns in their networking activity or its effects on stakeholder behaviour (though see Andrews et al. 2011 and Walker et al. 2007). It is quite possible that alternative types of networking are associated with varying levels of stakeholder support and that this is a product of the different logics guiding the intensity with which managers interact with different stakeholder groups. To explore these issues, this article combines a resource dependence perspective with ideas about different logics of action from institutional theory to address two key questions pertaining to managerial networking: Do managers exhibit distinctive patterns of networking behaviour? Do these patterns have divergent implications for the degree of support they experience from key stakeholder groups? To 
derive answers to these key questions, we analyse data from a survey of managers in local governments in England using multivariate statistical techniques.

In the first section of the paper, we apply resource dependence and institutional theory to the behaviour of managers in complex networked settings in the public sector. In doing so, we develop some broad expectations about the likely patterns of managerial networking in public service organizations, and the probable relationships between these patterns and the degree of support managers are likely to garner from key stakeholder groups. The data and methods we use to explore networking behaviour amongst local government officers and the stakeholder support that they experience are then described. Thereafter, evidence drawn from a fuzzy clustering analysis is presented on patterns of managerial networking, and the cluster membership functions entered in multivariate regression models examining the determinants of perceived stakeholder support. Finally, our findings are discussed and the theoretical and practical implications assessed.

\section{Managerial Networking in Public Service Organizations}

The shift towards the organization of policies and services in the public sector around notions of governance has heightened interest in managerial networking (Agranoff and McGuire 2001, 2003; O’Toole 1997). Networking, in general, typically incorporates the formal structural relationships embodied in networks and the actual behaviour of individual managers, as they seek to reduce the impact of resource dependencies on strategic and operational decisions (Sargent 2011). In service delivery organizations, this networking activity is usually aimed at carving out the relational space required to continually improve service quality. In this study, we focus on the behavioural role of managers in local public service organizations, which represent an especially interesting case for studying patterns of managerial networking because of the shift in the delivery of public services from hierarchies to the use of networks of multiple actors (Molin and Masella forthcoming).

According to resource dependence theory, the networking behaviour of managers is typically a product of attempts to influence or involve important stakeholders within the organizational environment (Pfeffer and Salancik 1978). Public organizations are required to deal with and reconcile the often conflicting demands of a multitude of important stakeholders, such as politicians, policy-makers and voluntary and private sector representatives (Rainey 1989). In England, local public service delivery networks are constituted by a diverse array of stakeholders, ranging from those closely associated with the organization (e.g. elected local representatives), to those in the local community (e.g. representatives of voluntary sector organizations and local business leaders), to those at the regional and national level (e.g. central government officials).

For local government managers, the pursuit of resource independence through interaction with different external stakeholder groups seems likely to take three principal forms. Firstly, it may involve an emphasis on networking to accrue financial, human and intellectual resources that can be used to improve the efficiency and effectiveness of local public services. On the one hand, this may be pursued by, proactively attracting partners to co-produce services, such as other local public and voluntary sector agencies to tackle wicked issues, like youth disorder, or local businesses to build support for economic development plans (Andrews et al. 2014). At the same time, it may also entail efforts to gain additional advice, guidance and support from regulatory agencies with responsibility 
for ensuring local governments are able to meet national service standards (Döring et al. 2015). This networking is largely undertaken for technical purposes to enable managers to better meet their service responsibilities, being underpinned by what institutional theorists would describe as a 'logic of consequences' - actions calculated to result in maximum benefit to the organization (Entwistle 2011).

Secondly, managerial networking at the local level may take the form of an emphasis on engagement with stakeholder groups higher up within the political hierarchy. This pattern of networking involves building support amongst politicians and policy-makers for preferred strategic and operational decisions, which, in turn, ensures that those decisions are seen to be the right ones by political principals (Moore 1995; Teske and Schneider 1994). Although managers may actively seek the approval of politicians and policy-makers, contact may also be a product of interactions initiated by those stakeholder groups, with managers being held to account for the perceived appropriateness of their actions (Walker et al. 2007). Managers that devote more time to networking with politicians and policy-makers are thus likely to have a keen sense of how the reputation of their organization is perceived by those actors (Carpenter and Krause 2012). Networking for reputational purposes is therefore mainly undertaken for the purposes of building and maintaining the external legitimacy of the organization, being shaped by what institutional theorists term a 'logic of appropriateness' - actions undertaken because they are perceived to establish the right sort of organizational identity (Entwistle 2011).

Thirdly, the networking of public managers may be driven solely by local circumstances. Local government managers may find that they are required to devote time to the expectations of local elected officials, whether because those politicians are questioning the strategic and operational decisions that are made by the ruling group or because the ruling group themselves need assistance to persuade local people of the merits of their decision-making (Entwistle et al. 2005). At the same time, managers may also need to devote additional attention to persuading partners of the merits of those decisions, for example, by encouraging local businesses to remain in the jurisdiction of the local authority rather than relocate to another adjoining one (Agranoff and McGuire 1998) or prioritizing certain service delivery objectives (O'Toole and Meier 2004). All of which indicates that this form of networking is inherently political in orientation, but is also guided by a 'logic of appropriateness', albeit one that is more shaped by local values and norms, than wider regional or national ones.

Finally, managerial networking may be entirely driven by the need to meet the demands of regulatory agencies. For English local governments, collaborative relationships are often mandated - that is, the product of statutory requirements to develop, organize and structure relationships with different actors and agencies (Andrews et al. 2014; Jones and Stewart 2009). Hence, local government managers who focus their networking efforts on policy-makers in central government may be doing so solely for tokenistic purposes, without any wider objective to gain reputational or political, let alone technical benefits for the organization.

\section{Managerial Networking and Stakeholder Support: Some Hypotheses}

Public managers' networking with external stakeholders takes a variety of different forms, ranging from the technical to the tokenistic, but is generally undertaken with a view to reducing resource dependence by securing vital resources of expertise, finance, 
political support or perceived legitimacy (Agranoff and McGuire 2001; Williams 2002). That said, there may be good reasons to think that different types of networking behaviour are likely to result in varying levels of support from stakeholders. Or, put differently, that some managerial networking strategies are more successful than others for reducing resource dependence.

Critical to the success of alternative types of networking behaviour are the underlying rationales for that behaviour and the relative value of the resources that managers are able to acquire from networking with specific stakeholder groups. In particular, it is likely that managers in local public service organizations will gain more from networking with those stakeholder groups that take an active interest in improving service quality rather than those that are primarily interested in holding managers to account. Hence, networking motivated by the "logic of consequences" may be more likely to generate positive results than that which is motivated by a "logic of appropriateness". There are several reasons why this may be so.

Firstly, the requirements of a consequential logic for interactions with stakeholders may be easier to interpret on the part of both parties to the interaction, and can thereby facilitate more effective negotiation of a shared agenda. Where interactions are based on the mutual calculation of expected returns, the interests of different parties may be more easily stated, understood and reconciled (March and Olsen 1998). Secondly, the potential for the negotiation of a genuinely shared collaborative agenda may be correspondingly higher where the actors involved in strategic interactions share certain core objectives (Andrews et al. 2015) - something that seems more likely for interactions based on a joint desire to improve concrete service delivery outcomes than for interactions relating to fuzzier notions of legitimacy and appropriateness. Likewise, where different actors share certain core objectives, it is also more likely that they will adhere to a similar set of professional priorities and preoccupations. From this perspective, similarities in professional identity and outlook may reflect an underlying service improvement institutional logic that facilitates successful interaction and could result in better networking outcomes (Döring et al. 2015). Given these arguments, technical networking seems especially likely to reduce problems of resource dependence and to enable managers to secure much needed support from stakeholder groups with a shared interest in improving public service provision. Hence, we anticipate that:

Hypothesis 1 (H1): Networking for technical purposes is positively related to perceived stakeholder support

Whereas networking driven by a logic of consequences seems likely to facilitate the kinds of open communication required to bring stakeholders together in pursuit of shared goals, interactions guided by a logic of appropriateness seem to be more likely to be plagued by indeterminacy and ambiguity (Saz-Carranza and Longo 2012). Reputational and political networking relies more heavily on symbolic processes of interaction, whereby what is or is not the right type of organizational behaviour emerges from more or less informal discussions between political principals and their agents. From a principal-agent perspective, the outcomes of such networking seem more likely to reflect the interests of the principal who is better able to set the agenda rather than the agents who seek affirmation and legitimacy (Geddes 2006). There is less scope for mutual exchange between principals and agents than there is between service delivery partners, and the 
terms of negotiation are more likely to be set in advance by the principal. For this reason, networking for reputational or political purposes may make it harder for public service managers to secure all the resources that they need on terms that are favourable to them. Again, several reasons may be advanced for this possibility.

In contrast with technically-orientated networking, networking for reputational and political purposes is beset with the problem of power dependence. Public service managers are ultimately accountable to elected politicians and policy-makers in higher levels of government, which, in turn, means they have less scope for defining what is or is not legitimate organizational behaviour (Geddes 2006). Since reputational and political networking is guided by a logic of appropriateness it is then ultimately shaped by assumptions and understandings about the roles and responsibilities of each of the actors that have been determined by the more powerful stakeholders. This undermines the potential for a shared professional logic to emerge, which can underpin agreement on how to pursue shared objectives.

Not only is the power dependence that afflicts reputational and political networking a constraint on the development of norms of effective collaboration and co-operation, it is also the likely source of problems associate with goal incongruence. Reputational and political interactions are undertaken by public service managers to secure approval for preferred strategic decisions. However, political principals are more likely to regard it as an opportunity to set their own agendas for the agents responsible for implementing public policies (Entwistle and Enticott 2007). Although the resolution of such challenges might result in better relations with oversight bodies and political principals, it is equally likely to have required that public service organizations compromise on their preferred priorities and adopt those of their principals (Cowell and Martin 2003). In these circumstances, public managers may be more sceptical about the value of the support that they have received from stakeholder groups. Thus, our second hypothesis is:

Hypothesis 2 (H2): Networking for reputational or political purposes is negatively related to perceived stakeholder support

Networking for tokenistic purposes is not guided by a logic of consequences because it is not undertaken with sufficient intensity for the possibility of positive outcomes from interactions with external stakeholders to be a consideration. Likewise, it is not shaped by a logic of appropriateness, as this requires a substantial commitment of time and resources to seek to persuade political principals of the merits of your management practices. Rather, tokenistic networking is driven by something like a logic of minimal compliance, and is undertaken principally to meet the mandated requirements for cooperation with key oversight bodies (Moseley and James 2008). As a result of the "bad faith" that this implies, it is unlikely to garner the same kind of levels of stakeholder support as technical, reputational or political networking.

Tokenistic networking is an indication that managers adhere to a reactive strategy for improving service delivery, doing only what is necessary to keep regulators at arm's length, rather than proactively seeking out ways to garner support from partners or greater legitimacy from political principals. While meeting mandatory requirements for interaction with policy-makers may enhance the perceived legitimacy of public service organizations, it is less likely to generate the close co-operation required to undergird collaborative home-grown strategic and operational decisions (Moseley and James 
2008). Furthermore, a minimal compliance logic is not conducive to the spirit of trust required to make interpersonal interactions an effective means for the co-creation of shared agendas (Agranoff and McGuire 2003). Where an agent is clearly doing no more than what is necessary to please the principal at any given moment, it breeds mistrust on the part of the principal who becomes less confident that the agent can be relied upon to respond effectively to changing circumstances. In fact, regulatory agencies have increasingly become concerned about the capacity of public service organizations for effectively managing their own affairs (Kelly 2006). For all these reasons, the third hypothesis is that:

Hypothesis 3 (H3): Networking for tokenistic purposes is negatively related to perceived stakeholder support

The connections between managerial networking and stakeholder support in public service organizations are modelled in Fig. 1.

\section{Data and Methods}

Data for this study were drawn from an email survey of managers in English local governments. These organizations are elected bodies, operating in territorially bounded geographical areas, which employ professional career staff, and receive over two-thirds of their income from UK central government. They are multi-purpose governments delivering services in the areas of education, social care, land-use planning, waste management, public housing, leisure and culture, and welfare benefits. In England at the time of the study there were 386 local governments of five types: 32 London boroughs, 36 metropolitan boroughs, and 46 unitary authorities mostly in urban areas delivering all of the services listed above; and in rural areas, 34 county councils

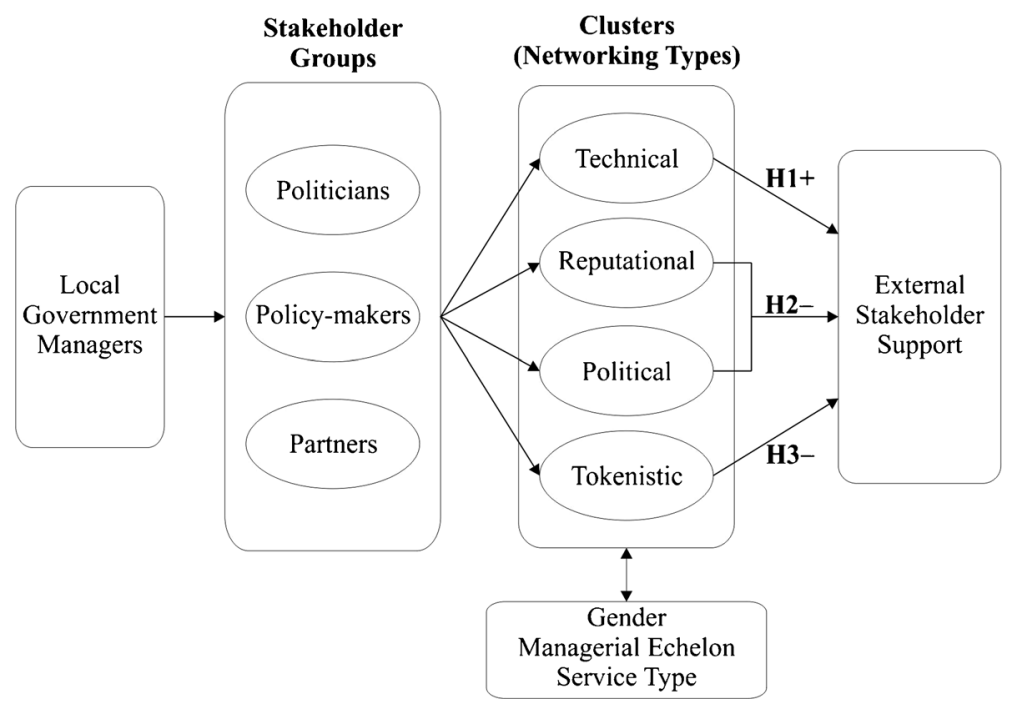

Fig. 1 Conceptual model 
administering education and social services, and 238 district councils providing welfare and regulatory services.

The survey was administered in late 2007. Email addresses for the entire population of the first three tiers of local government managers were drawn from a national contacts database, and questionnaires were then delivered as an EXCEL file attached to an email. The questionnaires were self-coding and converted to SPSS for analysis. To ensure we captured variations in network behaviour by managers at different levels in the organization (see Walker et al. 2007) we distributed the survey to chief executive officers, strategic directors, service heads and officers.

The chief executive officer (or head of paid service) and strategic directors (e.g. Director of Children's Services) have cross-organizational responsibilities for service delivery and improvement. Service heads are those senior managers with responsibility for the delivery and management of specific services (e.g. Head of School Organization and Planning and Head of Community Safety). Service officers are front-line supervisory managers focused on the process of delivery within specific service areas, such as Housing or Planning Officers. In each local government, questionnaires were sent to all chief executive officers and strategic directors, and all second and third-tier management level service officers across seven core service areas: benefits and revenues, education, environmental services (including waste management and environmental health), highways, housing, library and leisure and social care.

The number of staff surveyed varied across each type of local government due to the differing role and responsibilities of single and two-tier governments. The total number of potential informants was 6975, and the number of actual respondents was 1082 $(15.5 \%)$, of which $1008(14.5 \%)$ were complete in terms of the data necessary for this study. Responses were received from 28 London boroughs, 36 Metropolitan boroughs, 45 unitary authorities, 31 county councils and 188 district councils. Respondents included 42 chief executive officers, 260 strategic directors, 401 service heads, and 305 service officers. The local governments in this sample are representative of all local governments on key background characteristics, including socio-economic deprivation, ethnic diversity, performance, population and population density.

\section{Stakeholder Support}

To evaluate the level of support managers are able to garner from stakeholders, we draw upon a question from the survey asking respondents to rate the extent to which 'external stakeholders are supportive of the service' from 1 (strongly disagree) to 7 (strongly agree). Single item measures of this type that capture very narrowly specified constructs have been shown to exhibit high levels of reliability (Nagy 2002; Wanous and Hudy 2001). The mean level of perceived stakeholder support is 5.2 (standard deviation of 1.2), indicating that by and large external stakeholders are perceived to be supportive of the work local governments were doing at the time the study was carried out.

\section{Managerial Networking}

The survey from which our networking behaviour measures were taken explored informants' perceptions of management, performance and background variables (a copy of the full questionnaire is available on request from the authors). The survey sought to examine 
the reported networking behaviour of English local government officers in interacting with seven groups of important stakeholders in their environment.

The first group are 'politicians' some of whom are closely associated with the local government (elected members) and others with the national government (Members of Parliament (MPs)). These stakeholders are brought together by a concern with ensuring that the service providers are responsive to the demands of democratic accountability. Elected members are separate from the formal bureaucracy and represent local citizens' views over service delivery issues at the local level, as do MPs at the national level. Informants were also questioned about two key groups of national actors responsible for ensuring that the public interest is served by public service providers - central government officials and representatives of regulatory agencies. These 'policy-makers' tend to focus on issues of policy, oversight and finance, and because they are likely to be geographically removed from the immediate local government, managers may interact less frequently with them than other stakeholder groups. The final group of actors are those individuals representing potential 'partners' in service production. While these 'partners' may be primarily concerned with service delivery, they often also fulfil a wider brief. For example, local business leaders may play a civic leadership role, voluntary organizations may act as pressure groups and other public agencies may hold key mandates for specific policy initiatives.

Each informant was asked how often he or she interacted with each of these actors. A six-point scale was used to gauge the extent of their interaction, where $1=$ never, 2 = yearly, $3=$ monthly, $4=$ weekly, $5=$ more than once a week and $6=$ daily. The descriptive statistics for interactions with each group of actors are presented in Table 1. Factor analysis (using varimax rotation with Kaiser Normalization) was then used to identify the extent to which patterns of managerial networking did in fact coalesce around distinctive sets of actors. Based on the principle of identifying components (factors) with eigenvalues greater than one (see discussion earlier), three factors are identified that collectively account for $68 \%$ of the variance contained in the variables. As shown in Table 1, three factors are identified, each reflecting the different types of actors with whom local government managers' interact: Politicians (Factor 1), Policymakers (Factor 2) and Partners (Factor 3). Although the scale reliability for each factor is comparatively low (Cronbach's alpha of about 0.6), this is acceptable for the kind of exploratory analysis we have undertaken here (Loewenthal 1996).

\section{Control Variables}

Upper echelon theory suggests that the personal characteristics of senior managers have a direct bearing on how they choose to interpret the environment that their organization confronts (Hambrick and Mason 1984). When gauging the level of support that they receive from external stakeholders, managers are therefore likely to be influenced by the values and experiences that have shaped their personal identity. Observable characteristics, such as the gender and tenure of managers are all hypothesised to play an important part in shaping their perceptions. Research has suggested that women are more likely than men to involve a wide range of stakeholders in decision-making (Fox and Schuhmann 1999), and so it may be anticipated that female managers perceive higher levels of stakeholder support than their male colleagues. By contrast, individuals who have been employed within an organization for a longer time period may be more 
Table 1 Managerial networking: interaction with different actors $(1=$ never to $6=$ daily $)$

\begin{tabular}{llllll}
\hline Actor group & Mean & SD & Factor 1 & Factor 2 & Factor 3 \\
\hline Elected members & 4.749 & 1.178 & 0.835 & 0.091 & 0.165 \\
MPs & 2.454 & 0.961 & 0.768 & 0.260 & 0.100 \\
Central government officials & 2.616 & 0.864 & 0.234 & 0.741 & 0.136 \\
Regulatory agencies & 2.586 & 0.924 & 0.132 & 0.823 & 0.093 \\
Local business leaders & 2.516 & 1.120 & 0.467 & 0.124 & 0.573 \\
Voluntary sector organisations & 2.987 & 1.036 & 0.150 & 0.045 & 0.869 \\
Other public agencies & 3.117 & 1.074 & 0.016 & 0.519 & 0.652 \\
Eigenvalue & & & 1.600 & 1.589 & 1.573 \\
Cronbach alpha & & & 0.610 & 0.570 & 0.650 \\
\hline
\end{tabular}

reluctant to reach out to stakeholders than their younger or more ambitious counterparts (Barker and Mueller 2002; Hambrick and Fukutomi 1991).

Variations in perceived stakeholder support are also conceivably likely for managers located in different places in the organizational hierarchy and between different services. Managers fulfil particular roles in the hierarchy and have differing levels of authority and functional responsibility and roles. Senior public managers will likely manage upwards to politicians and beyond into the wider organizational environment to a greater degree than those lower down the hierarchy. Moreover, evidence suggests that senior managers tend to think strategically and positively about their organizations (Bowman and Ambrosini 1997; Golden 1992). Middle managers offer a different perspective. In multipurpose public organizations, these officers are responsible for specific programmes and decision-making in relation to, typically, one organizational sub-unit. The priorities of frontline managers are also somewhat unique. These officials tend to focus on the task-related demands of their jobs and the needs of the clientele they are serving (Lipsky 1980). Given the different functional roles ascribed to different groups of managers, and empirical evidence showing these groups exhibit different attitudes and behaviour, we believe groups of internal managers are likely to have varying perceptions of stakeholder support. Hence, it is important to control for the potential influence of position within the organizational hierarchy on the relationships we study.

English local governments are large complex multipurpose organizations delivering a range of services. It is, therefore, likely that variations in goals and task will result in alternative attitudes and behaviours in different service areas. Some of the more noticeable differences would be between services with higher levels of professionalization and those more focused around administration. For example, managers in education and social services may be expected to interact more with users and stakeholders in the local community, whereas managers administrating benefits and revenue services are likely to be inward focused. Likewise, managers in regulatory or technical services gain knowledge and information about service delivery from managers in other public agencies, and so are more externally-orientated than those working in administrative departments. To capture potential variations in perceived stakeholder support relating to the mission of the department in which managers work, we include dichotomous variables coded 1 for managers working in corporate (i.e. central administration, HR) and distributive (i.e. education, social care) service 
areas and 0 otherwise, with managers working in regulatory services (i.e. waste management, land use planning) taken as the reference category. Descriptive statistics for all the control variables are shown in Table 2.

\section{Findings}

\section{Fuzzy C-Means Clustering of Managerial Networking}

Clustering is a well-known technique for finding groups in data (see Frayley and Raftery 1998). In this paper we use fuzzy c-means clustering (Bezdek 1980, 1981) which, unlike crisp $k$-means clustering (Ketchen and Shook 1996), and the Ward's method utilised by Janssens et al. (2003), recognises that each object may be associated with more than one cluster. Degrees of cluster membership are indicated by a membership coefficient (see Zadeh 1965). Fuzzy clustering is a particularly appropriate technique for discerning patterns amongst ambiguous data, such as in the investigation of managerial networking, where managers can display varied combinations of interaction with, in this case, politicians, policy-makers and partners. Hence, our fuzzy cluster analysis is performed with the understanding that a local government manager may be associated, to varying degrees, with different clusters of networking behaviour.

We investigated four clusters, without loss of generality. The selection of four clusters was based on their theoretical validity (Ketchen and Shook 1996), although three, five and six cluster models were also considered in earlier stages of data analysis. The clusters represent groups of local government managers, differentiated by the extent of their networking with politicians, policy-makers and partners (e.g. the three factor values). The notched box plot $^{1}$ presented in Fig. 2 shows the mean factor scores for interactions with different groups of actors for each cluster of networking behaviour (see McDermott et al. 2013, for previous use of this form of visualisation). The individual cluster means were found by grouping managers based on majority association. Comparison of these means enables us to discern different types of managerial networking, described here as Technical (TEC), Reputational (REP), Political (POL) and Tokenistic (TOK).

The technical networking cluster is composed of managers who interact very intensively with partners - to a vastly greater extent than any other cluster - and also policy-makers, but not so much with politicians. The reputational networking cluster is composed of managers who interact very intensively with politicians and also policymakers, but not with partners. The political networking cluster is composed of managers who interact quite intensively with politicians and local partners, but not policymakers. The tokenistic networking cluster is composed of managers who interact quite intensively with policy-makers but very little with politicians and partners. In terms of the numbers of managers associated with each pattern of networking, 219 were primarily associated with networking for technical purposes, 285 with networking for reputational purposes, 240 with networking for political purposes and 264 with

\footnotetext{
${ }^{1}$ Within a notched box plot, the line inside the box is the median, the notch away from the median is the median confidence interval (height 3.14 times the inter-quartile range divided by the square root of the total weight of the data), the bottom and top of the box are the 1st and 3rd quartiles, and the bottom and top whiskers 1.5 the inter-quartile range (not extending past the range of the data), further points are potential outliers.
} 
Table 2 Descriptive statistics

\begin{tabular}{lrr}
\hline & Mean & \multicolumn{1}{c}{ SD } \\
\hline Chief Executive Officer & 0.042 & 0.200 \\
Corporate director & 0.258 & 0.438 \\
Head of Service & 0.398 & 0.490 \\
Service manager & 1.887 & 4.255 \\
Corporate department & 0.420 & 0.494 \\
Distributive department & 0.274 & 0.446 \\
Regulatory department & 0.307 & 0.461 \\
Men & 0.658 & 0.475 \\
Years of service & 12.497 & 10.753 \\
\hline
\end{tabular}

tokenistic networking. All of which highlights that most of the networking undertaken by our sample of managers was driven by a logic of appropriateness rather than a logic of consequences or minimal compliance.

\section{Managerial Networking and Stakeholder Support}

This section considers the relationship between the managerial networking types and stakeholder support. To begin, in Table 3 we compare the mean levels of stakeholder support across the different clusters of managerial networking behaviour by carrying out post-hoc statistical tests to evaluate whether there are statistically significant differences in levels of perceived support between the clusters.

The results presented in Table 3 indicate that perceived stakeholder support is highest amongst the managers associated with the technical cluster, followed by the reputational, political and then the tokenistic clusters - broadly in line with the arguments developed earlier in the paper. Furthermore, there are statistically significant differences between the four clusters in four out of six cases. The post-hoc analyses identify significant differences in the strength of stakeholder support, between the technical networking cluster and all three other clusters; and between the reputational and tokenistic networking clusters. These results suggest that networking driven by a logic of consequences is more likely to generate stakeholder support than that guided by a logic of appropriateness. In addition, it seems that reputational networking is a better strategy for reducing resource dependence than tokenistic networking. Nevertheless, to form stronger conclusions about the relative merits of each type of networking for resource dependence it is necessary to analyse variations in perceived stakeholder support when controlling for relevant individual characteristics.

Hierarchical regression analyses of the relationship between types of managerial networking and perceived stakeholder support are shown in Table 4 (as employed in Janssens et al. 2003). To facilitate the regression analyses, the four clusters were transformed into dummy variables using the membership values for the positive cluster values generated from the fuzzy $c$-means clustering rather than a single positive value as would be the case for crisp-set clustering techniques (a development on the approach in Janssens et al. 2003). Four separate regression equations were calculated, with a different networking cluster used as a reference category for each model. We are then able to compare the level of perceived stakeholder 


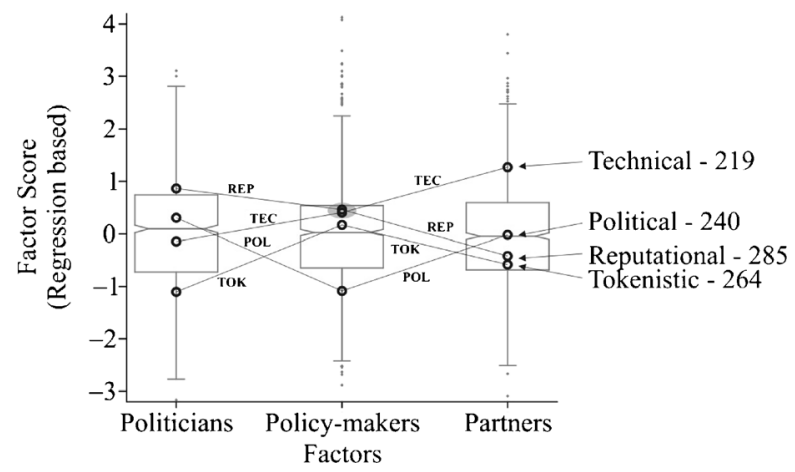

Fig. 2 Constituent factor means for managerial networking clusters

support of three (dummy scored) clusters with the remaining fourth cluster that serves as the reference category.

In terms of the control variables, the results presented in Table 4 indicate that gender makes a difference to how managers perceive the support of external stakeholders. The coefficient for male managers is negative, as anticipated, and statistically significant, highlighting that women managers perceive higher levels of stakeholder support. By contrast, the coefficient for organizational tenure is not statistically significant, indicating that length of service does not influence how managers perceive stakeholder support. In accordance with our expectations, it seems that managers in the upper echelons of the organization perceive support from stakeholders to be higher than those in the lowest echelon - the coefficients for CEO, corporate director and Head of Service are all positive and statistically significant. Finally, the type of department in which managers work appears to be important, with those working in corporate departments, unsurprisingly, perceiving support from external stakeholders to be lower than those in distributive or regulatory departments.

Turning to our main variables of interest, the estimates presented in Table 4 confirm that technical networking is associated with the highest level of perceived stakeholder support: the coefficient for the technical networking variable is positive and statistically significant in all four regression equations. Thus, our first hypothesis regarding technical

Table 3 Perceived stakeholder support across networking clusters

\begin{tabular}{llll}
\hline & \multicolumn{2}{l}{ Technical (5.58) $>$ Reputational (5.27) $>$ Political (5.02) $>$ Tokenistic (4.97) } \\
\cline { 2 - 4 } & Mean Difference & Standard Error & Significance \\
\hline Technical and Reputational & $0.31^{* *}$ & 0.11 & 0.02 \\
Technical and Political & $0.56^{* *}$ & 0.11 & 0.00 \\
Technical and Tokenistic & $0.61^{* *}$ & 0.11 & 0.00 \\
Reputational and Political & 0.25 & 0.11 & 0.12 \\
Reputational and Tokenistic & $0.30^{* *}$ & 0.10 & 0.02 \\
Political and Tokenistic & 0.05 & 0.11 & 1.00 \\
\hline
\end{tabular}

Mean values for stakeholder support shown in brackets. Bonferroni’s post-hoc tests. $* * p \leq 0.01$ (two-tailed tests) 
Table 4 Managerial networking and stakeholder support

\begin{tabular}{lllll}
\hline & Tokenistic & Political & Reputational & Technical \\
\hline Tokenistic & - & $.001(.980)$ & $-.098^{*}(.011)$ & $-.206 * * *(.000)$ \\
Political & $-.001(.980)$ & - & $-.089 *(.018)$ & $-.186 * * *(.000)$ \\
Reputational & $.106^{*}(.011)$ & $.101 *(.018)$ & - & $-.110^{* *}(.006)$ \\
Technical & $.189 * *(.000)$ & $.190 * * *(.000)$ & $.099 * *(.006)$ & $.099 * *(.006)$ \\
Male & $-.058+(.066)$ & $-.058+(.066)$ & $-.058+(.066)$ & $-.058+(.066)$ \\
Years of service in the organization & $.004(.907)$ & $.004(.907)$ & $.004(.907)$ & $.004(.907)$ \\
Chief Executive Officer & $.067+(.053)$ & $.067+(.053)$ & $.067+(.053)$ & $.067+(.053)$ \\
Corporate director & $.068+(.075)$ & $.068+(.075)$ & $.068+(.075)$ & $.068+(.075)$ \\
Head of Service & $.065+(.082)$ & $.065+(.082)$ & $.065+(.082)$ & $.065+(.082)$ \\
Corporate service department & $-.231 *(.015)$ & $-.231 *(.015)$ & $-.231 *(.015)$ & $-.231 *(.015)$ \\
Distributive service department & $-.026(.797)$ & $-.026(.797)$ & $-.026(.797)$ & $-.026(.797)$ \\
Adj. R2 & $.043 * *$ & $.043 * * *$ & $.043 * * *$ & $.043 * * *$ \\
F & $5.557 * * *$ & $5.557 * * *$ & $5.557 * * *$ & $5.557 * * *$ \\
\hline
\end{tabular}

${ }^{\mathrm{a}}$ Standardized beta coefficients; $+p<. .10 ; * p<.05 ; * * p<.01 ; * * * p<.001 . P$ values shown in brackets

networking (H1) receives strong support. Managerial networking guided by a logic of consequences seems to be an effective strategy for reducing resource dependence. By contrast, each of the other types of networking are associated with lower levels of perceived stakeholder support, thereby affirming our second (H2) and third (H3) hypotheses regarding the merits of networking driven by a logic of appropriateness or a logic of minimal compliance. That said, there are interesting differences between reputational networking and political and tokenistic networking, which are worth discussing.

Although networking for reputational purposes appears less likely to improve stakeholder support than networking for technical purposes, it is more likely to do so than networking for either political or tokenistic purposes. Since reputational networking is more strongly shaped by a logic of appropriateness than political networking, this is suggestive of the possibility that the strength of commitment to a coherent logic of action may be an important strategy for dealing with the dilemmas posed by resource dependence - though a logic of minimal compliance seems unlikely to lead to desirable results. Interestingly, political and tokenistic networking are associated with similar, low levels of stakeholder support, which points towards the difficulties associated with a more reactive approach to engaging with external stakeholders.

\section{Conclusion}

This study has examined the relationship between alternative patterns of managerial networking and the support that public service managers receive from external stakeholders. Fuzzy cluster analysis identified four different patterns of managerial networking, reflecting varying levels of interaction with key stakeholder groups: technical, reputational, political and tokenistic. Findings from multivariate hierarchical regression analyses suggest that networking for technical purposes is associated with higher levels 
of stakeholder support than all the other types of networking, with political and tokenistic networking associated with the lowest level of stakeholder support. These findings have important theoretical and practical implications.

Resource dependency theory is one of the most important schools of thought in organization studies. Nevertheless, comparatively few studies have systematically examined the relative success of strategies for reducing resource dependence or eliciting stakeholder support among managers in public service organizations. In particular, prior research has largely focused on the board composition of private firms (e.g. Hillman et al. 2000), horizontal mergers and strategic alliances between corporations (e.g. Boyd 1990) or the revenue generation strategies of nonprofit organizations (e.g. Froelich 1999). The analysis presented here highlights that managers in public service organizations adopt different patterns of networking with external stakeholders and that those different patterns of networking have varying implications for the level of support that managers receive from stakeholders. Drawing on institutional theory, we suggest that networking guided by a logic of consequences appears to be a more successful strategy for reducing resource dependence than networking driven by a logic of appropriateness. A logic of minimal compliance appears to be an especially ineffective strategy for garnering stakeholder support. These findings are not only valuable in themselves but also illustrate the value of bringing together resource dependency and institutional theories in order to better understand interorganizational relations.

While the statistical findings provide support for our hypothesised relationships between types of networking and stakeholder support, the study has clear limitations. In particular, the analysis presented here has examined a particular group of public service managers working within a particular set of public organizations during a specific time period. It would therefore be important to identify whether patterns of networking and stakeholder support differ over other time periods and in other organizational settings in the public sector. In addition, although we offer a novel test of resource dependence theory in the public sector, we draw upon a crosssectional dataset that does not enable us to fully tease out the causal effects of changes in networking behaviour and stakeholder support. Panel data incorporating information on networking behaviour and on levels of stakeholder support would undoubtedly enable the relationship between the two to be investigated in even more depth. Moreover, we rely on managers' perceptions to test our hypotheses, but it may be possible to draw on other sources of data to explore patterns of networking behaviour, such as minutes from meetings between managers and stakeholders, as well as developing measures of resource dependence that directly capture the tangible resources stakeholder groups are able to share with public service organizations.

In summary, our study has highlighted the role that different types of managerial networking can play in shaping levels of stakeholder support for public service organizations. In doing so, we have identified logics of action that are more or less successful strategies for public service managers seeking to reduce problems associated with resource dependence. Further research identifying and comparing the relative importance of other managerial and organizational approaches to managing stakeholder expectations would add vital knowledge on the forces that shape resource dependence in public service organizations. 
Open Access This article is distributed under the terms of the Creative Commons Attribution 4.0 International License (http://creativecommons.org/licenses/by/4.0/), which permits unrestricted use, distribution, and reproduction in any medium, provided you give appropriate credit to the original author(s) and the source, provide a link to the Creative Commons license, and indicate if changes were made.

\section{References}

Agranoff, R., \& McGuire, M. (1998). Multinetwork management: collaboration and the hollow state in local economic policy. Journal of Public Administration Research and Theory, 8(1), 67-91.

Agranoff, R., \& McGuire, M. (2001). Big questions in public network management research. Journal of Public Administration Research and Theory, 11(3), 295-326.

Agranoff, R., \& McGuire, M. (2003). Collaborative public management: New strategies for local governments. Washington DC: Georgetown University Press.

Andrews, R., Boyne, G. A., Meier, K. J., O’Toole, L. J., \& Walker, R. M. (2011). Environmental and organizational determinants of external networking. American Review of Public Administration, 41(4), 355-374.

Andrews, R., Downe, J., \& Guarneros-Meza, V. (2014). Contracting for cohesion: can local area agreements make a difference? Policy \& Politics, 42(4), 477-493.

Andrews, R., Esteve, M., \& Ysa, T. (2015). Public-private joint ventures: mixing oil and water? Public Money \& Management, 35(4), 265-272.

Barker, V. L., \& Mueller, G. C. (2002). CEO characteristics and firm R\&D spending. Management Science, 48(6), 782-801.

Bezdek, J. C. (1980). A convergence theorem for the fuzzy ISODATA clustering algorithms. IEEE Transactions on Pattern Analysis and Machine Intelligence, PAMI, 2, 1-8.

Bezdek, J. C. (1981). Pattern recognition with fuzzy objective function algorithms. New York: Plenum Press.

Bowman, C., \& Ambrosini, V. (1997). Perceptions of strategic priorities, consensus and firm performance. Journal of Management Studies, 34(2), 241-258.

Boyd, B. K. (1990). Corporate linkages and organizational environment: a test of the resource dependence model. Strategic Management Journal, 11(6), 419-430.

Carpenter, D. P., \& Krause, G. A. (2012). Reputation and public administration. Public Administration Review, 72(1), 26-32.

Cowell, R. J., \& Martin, S. J. (2003). The joy of joining up: modes of integrating the local government modernisation agenda. Environment and Planning C - Government and Policy, 21(2), 159-179.

Döring, H., Downe, J., \& Martin, S. J. (2015). Regulating public services: how public managers respond to external performance assessment. Public Administration Review, 75(6), 867-877.

Entwistle, T. (2011). For appropriateness or consequences: explaining organizational change in English local government. Public Administration, 89(2), 661-680.

Entwistle, T., \& Enticott, G. (2007). Who or what sets the agenda? The case of rural issues in England's local public service agreements. Policy Studies, 28(3), 193-208.

Entwistle, T., Enticott, G., \& Martin, S. J. (2005). Leadership and service improvement: dual elites or dynamic dependency? Local Government Studies, 31(5), 541-554.

Fox, R. L., \& Schuhmann, R. A. (1999). Gender and local government: a comparison of women and men city managers. Public Administration Review, 59(3), 231-242.

Frayley, C., \& Raftery, E. (1998). How many clusters? Which clustering method? Answers via model-based cluster analysis. The Computer Journal, 41(8), 578-588.

Froelich, K. A. (1999). Diversification of revenue strategies: evolving resource dependence in nonprofit organizations. Nonprofit and Voluntary Sector Quarterly, 28(3), 246-268.

Geddes, M. (2006). Partnership and the limits to local governance in England: institutionalist analysis and neoliberalism. International Journal of Urban and Regional Research, 30(1), 76-97.

Golden, B. R. (1992). The past is the past-or is it? The use of retrospective accounts as indicators of past strategy. Academy of Management Journal, 35(4), 848-860.

Hambrick, D. C., \& Fukutomi, G. D. S. (1991). The seasons of a CEO's tenure. Academy of Management Review, 16(4), 719-742.

Hambrick, D. C., \& Mason, P. A. (1984). Upper echelons: the organization as a reflection of its top managers. Academy of Management Review, 9(2), 193-206. 
Henttonen, K., Lahikainen, K., \& Jauhiainen, T. (forthcoming). Governance mechanisms in multi-party nonprofit collaboration. Public Organization Review

Hillman, A. J., Cannella, A. A., \& Paetzold, R. L. (2000). The resource dependence role of corporate directors: strategic adaptation of board composition in response to environmental change. Journal of Management Studies, 47(2), 235-256.

Janssens, M., Sels, L., \& Van Den Brande, I. (2003). Multiple types of psychological contracts: a six-cluster solution. Human Relations, 56(11), 1349-1378.

Jones, G., \& Stewart, J. (2009). Accountability in public partnerships - the case of local strategic partnerships. Public Money \& Management, 29(1), 59-64.

Kaiser, H. F. (1960). The application of electronic computers to factor analysis. Educational and Psychological Measurement, 20(1), 141-151.

Kelly, J. (2006). Central regulation of English local authorities: an example of meta-governance? Public Administration, 84(3), 603-621.

Ketchen Jr., D. J., \& Shook, C. L. (1996). The application of cluster analysis in strategic management research: an analysis and critique. Strategic Management Journal, 17(6), 441-458.

Lipsky, M. (1980). Street-level bureaucracy: dilemmas of the individual in public services. New York: Russell Sage Foundation.

Loewenthal, K. M. (1996). An introduction to psychological tests and scales. London: UCL Press.

March, J. G., \& Olsen, J. P. (1998). The institutional dynamics of international political orders. International Organization, 52(4), 943-969.

McDermott, A., Heffernan, M., \& Beynon, M. J. (2013). When the nature of employment matters in the employment relationship: a cluster analysis of the psychological contract and organizational commitment in the non-profit sector. International Journal of Human Resource Management, 24(7), 1490-1518.

Molin, M. D., \& Masella, C. (forthcoming). From fragmentation to comprehensiveness in network governance. Public Organization Review

Molina, A. L. (forthcoming). A manager is a manager is a manager? Race and managerial impact on organizational performance. Public Organization Review

Moore, M. H. (1995). Creating public value: strategic management in government. Cambridge, MA: Harvard University Press.

Moseley, A., \& James, O. (2008). Central state steering of local collaboration: assessing the impact of tools of meta-governance in homelessness services in England. Public Organization Review, $8(2), 117-136$.

Nagy, M. S. (2002). Using a single-item approach to measure facet job satisfaction. Journal of Occupational and Organizational Psychology, 75(1), 77-86.

O’Toole Jr., L. J. (1997). Treating networks seriously: practical and research-based agendas in public administration. Public Administration Review, 57(2), 45-52.

O’Toole Jr., L. J., \& Meier, K. J. (2004). Desperately seeking Selznick: cooptation and the dark side of public management in networks. Public Administration Review, 64(6), 681-693.

Oliver, C. (1991). Strategic responses to institutional processes. Academy of Management Review, 16(1), 145179.

Pfeffer, J. (1987). A resource dependence perspective on interorganizational relations. In M. S. Mizruchi, \& M. Schwartz (Eds.), Intercorporate relations: The structural analysis of business (pp. 22-55). Cambridge, UK: Cambridge University Press.

Pfeffer, J., \& Salancik, G. (1978). The external control of organizations: a resource dependence perspective. New York: Harper\&Row

Rainey, H. G. (1989). Public management - recent research on the political context and managerial roles, structures and behaviors. Journal of Management, 15(2), 229-250.

Sargent, S. (2011). Modeling network management: an examination of internal and external strategies. Public Organization Review

Saz-Carranza, A., \& Longo, F. (2012). Managing competing institutional logics in public-private joint ventures. Public Management Review, 14(3), 331-357.

Scott, W. R. (2003). Organizations: rational, natural, and open systems (5th ed., ). Upper Saddle River, NJ: Prentice Hall.

Teske, P., \& Schneider, M. (1994). The bureaucratic entrepreneur: the case of city managers. Public Administration Review, 54(4), 331-340. 
Walker, R. M., O’Toole, L. J., \& Meier, K. J. (2007). Its where you're at that matters: the networking behaviour of English local government officers. Public Administration, 85(3), 739-756.

Wanous, J. P., \& Hudy, M. J. (2001). Single-item reliability: a replication and extension. Organizational Research Methods, 4(4), 361-375.

Williams, P. (2002). The competent boundary spanner. Public Administration, 80(1), 103-124.

Zadeh, L. A. (1965). Fuzzy sets. Information and Control, 8(3), 338-353.

Rhys Andrews PhD., is Professor of Public Management at Cardiff Business School. His research interests include strategic management, organizational structures and public service performance. He has published in such journals as Journal of Public Administration Research and Theory, Public Administration and Public Administration Review.

Malcolm J. Beynon PhD., is Professor of Uncertain Reasoning in Business and Management at Cardiff Business School. His research interests include the development and application of Dempster-Shafer theory and Fuzzy Set theory within organizational settings. He has published in journals such as European Journal of Operational Research, Journal of Public Administration Research and Theory and Omega-International Journal of Management Science. 